\title{
Research of Social Transformation and Urban Community Sports
}

\author{
Jie Zhang ${ }^{1}$ \\ ${ }^{1}$ Department of physical education, Yulin university, Yulin Shaanxi 719000 \\ 54892713@163.com
}

Keywords: Social Transformation; Urban Community; Sports Development

\begin{abstract}
Social transformation is a general feature of today's Chinese society, and it is based on the changes of social structure as the main content, covering all areas of society overall change. Current social transformation of China constituted by two profound changes: First, the transition system, the second is the transition structure where economic transition affects the internal structure of society changes, changes in social structure and promote the deepening of economic transition who depend on each other, support each other, work together to promote the collapse of the old system to create new institutional system difficult process. Social transformation is bound to promote the social management system transformation cities.
\end{abstract}

\section{Introduction}

Social Transformation generally refers to society as a whole transition from traditional to modern, that is, the process of social modernization. The historical process of China's social transformation is very complex, meaning very important, it will complete a backward country to achieve modernization and the great cause of national rejuvenation. Current Social Transformation of China constituted by two profound changes: First, the transition regime, from planned economy to market economy transition; the second is the transition structure from agriculture, rural, closed traditional society to an industrial and the town, open modern social change. Economic transition in which changes affecting the internal structure of society, changes in social structure and promote the deepening of economic transition, the two depend on each other, support each other, work together to promote the collapse of the old system to create a new institutional system difficult process. At present, China's overall positive development is in the first modernization period. Social Transformation has and will continue to make all aspects of social development in China undergo major changes, also enable the development of urban community sports especially sports major changes. Transition and transformation of the social organization of Chinese social economy triggered a change in urban social management system, thus loosening the decades of entrenched "unit system", wake the development of Chinese urban communities. The mid-1980s the rise of community service, community building for the management of urban Chinese society has injected new vitality, and community services, community building almost simultaneous rise of urban community sport as a special kind of community cultural activities and new forms of social sports in urban management and social sports development in China has played a unique role.

\section{Community Development and Sports of China Urban Communities}

In 1954, the Central People's Government Ministry of the Interior issued a notice on the establishment of district offices and neighborhood committees, each Hall Street was renamed Office of the streets; the same year, the Standing Committee of National People's Congress through the "city streets Office organized Ordinance" (1997 February re-enactment) and "urban residents' committees organize Ordinance" (December 1980 re-enactment). The name of the country was unified neighborhood offices, nature, tasks and institutional settings, set to the neighborhood, the nature, tasks, functions, legal form to be determined. Clearly defined neighborhood committee is a resident self-management, self-education, self-service mass self-organization, and the neighborhood is also a comprehensive restructuring and conversion; so, basically formed as a sub-district offices and national grassroots political power institutions as regional social self-organized groups of 
residents committee mutual convergence of social grassroots organization pattern. As the district government agency, street office usually under the jurisdiction of grain management, Houses, police station, which is stationed in the various functional departments of district authorities. Domestic sports research community, the rise in the late 1980s, research mainly involves the concept of community sports, features, management system, present characteristics, organizational development, development mode from the content community sports studies, the preliminary research focused on the basic theory, such as on defining the concept more, in recent years, gradually shifted to research and development, indicating that Community Sports maturity.

\section{Social Transformation Influence on Social Development of the City Sports}

Market-oriented is the impact of competitive mechanisms. Transition economies are in transition from a planned economy to a market economy. Market economy system using the law of value, the law of supply and demand and competition rules to the allocation of resources as the basic way, inevitably breed a competitive mechanism and elimination mechanism, not only the economy, but also the social sphere is also facing a new kind of external pressure. This external pressure on the formation and strengthening of competition in the social field of sports consciousness and sense of efficiency will have a positive impact.

The government behavior changes. The necessary requirements for countries with economies in transition are to redefine and change the functions of government action. Transformation of government functions, compress the size of government, adjustment of government institutions, the reform of government restraint mechanism, and strengthen economic function, change the "witch hunt", "regardless of the political community," the situation has become inevitable government reform. With the implementation of government functions and the relationship between government and enterprises and other reform measures separate administrative unit settings no longer correspond to the industrial development in accordance with the principle, but to invest in accordance with the principles of the market economy under the government functions, design. This is the fundamental solution to the dislocation of government functions, overcome bloated, overstaffed administrative units, transitional revolutionary measures consumption of resources. Government administrative functions of converting comprises four aspects: First, the original micro-economic management and regulation of the steering macroeconomic management and regulation; the second is the original pipe business steering tubes market; the third is the rule of man from the original plan of economic management to the legal system of the planned economy; Fourth, the implementation of a comprehensive and high-containment direct intervention of management to all-round opening of economic life. Truly separates public affairs separate, separate government agency and corporate social separation. The change of sport function of government, we must first achieve a reasonable definition of sports functions of government, separation of management truly, outside the office moved to social functions, attention and the role of non-governmental sports organizations, to achieve small government, big society reform goals.

\section{Community Sports Development, Analysis and Recommendations}

Status Survey: "Missing field facility" is one of the top three factors that affected residents to participate in sports activities; "crowded field" is the first major difficulty faced by sports activities; "construction of sports facilities" is required to solve urban residents The primary problem of Community Sports (75.1\% of residents to solve this problem); residents are not satisfied with the sports facilities was $\mathbf{5 1 . 8}$ percent; visible community sports facility has become the primary factor restricting the development of urban community sport, the strengthening of community sports venues and facilities construction is welcomed. However, construction of community sports and other public facilities construction community, as in past years under the influence of the "first work life," the concept of urban development, too many outstanding loans, not a moment can be resolved. Also, because over the years the impact "unit system", regular stadiums community is almost zero (According to the 1995 survey, has built stadiums in $67.17 \%$ in schools, $22.09 \%$ in 
factories, mines, enterprises, military units, 2.34 percent in the sports system Faced with this situation, to solve the problem sports facilities must take a new integration of resources combined with the existing road.

Field Facilities Planning and Construction. Since 1997, the State Sports General Administration of using sports lottery in urban communities with the construction of major projects in the fitness path of the "National Fitness Project", in improving the health conditions of residents played a big role. In 2002, the State Sports General Administration of sports lottery as a guide to use the funds to start construction in the country, "National Fitness Center", also achieved remarkable results. But with the arrival of well-off society, people's demand for the rapid growth of sports, sports lottery investment alone to solve the problem of community sports grounds and facilities, can be described as inadequate. So, how to solve the construction of sports facilities has become an important social problem of the Community Sports Development.

First, it must implement institutional management for supporting the construction of new construction, renovation, expansion of sports facilities in residential areas. People's Republic of China national standard "Urban Residential Area Planning Design Code", 1993 jointly issued by the State Bureau of Technical Supervision and the Ministry of Construction, was revised in 1998, "Urban Residential Area Planning and Design Standards" provides 6.0.3 Terms: Public Service Facilities in "land use control indicators Style" for the residential building area 125-245 square meters / thousand land area 225-645 meters/thousand. 2 Although the "Urban Residential Area Planning Design Code" stylistic land with specific control targets, the whole land of culture and sports department of a mixed sports is no way to monitor the implementation, in addition to the construction sector did not put "style land at the time of acceptance of the construction project control targets "as a mandatory performance indicators, so there is often no planning or have stadium construction, or to reserve space for other purposes sports situation (few developers have now tasted the sweetness of the construction of sports facilities but more developers are reluctant to spend money on sports facility construction).

Second, the standard sports facilities sports to consider the needs of residents of different economic conditions. The concept of social services of general international practice by the welfare services, public services and citizens' personal services or socially oriented private service called socialization 3 parts. Welfare services refer to services provided by the government free of charge, public service refers to government subsidies unprofitable business services, private services means commercial (profit-type) services. China's urban distribution of the existing sports facilities were more than two and less in the middle of the state.

Integration of Resources on Sports Facilities. Stadium is the integration of resources in urban schools, units, streets three parts stadium resource regulation and complementary to each other in order to achieve a total of sports resources, shared state. With the development of the social economy, people's growing demand for sport. Increase public sports demand growth will inevitably bring sports resource requirements. Since the founding, although the state investment in the construction of a large number of sports venues, but far behind the growth in demand for sport, and because over the years under the planned economy system "fragmented" situation, making an already inadequate resources stadium No use to maximize its effectiveness, resulting in idle and waste part of sports resources.

Economic transition system, the inevitable occurs: Due to the integration of social action units weakened, the new system has not yet formed social integration, social discrete, social disorder, uncontrolled phenomena occur when society; the introduction of market mechanisms, will inevitably produce the urban population The new issue of structural change and the "new poor class" appears and so on. Planned economy "unit control system" 1 will gradually be "Community control system" 2 replaced. Social change to the community adds many new functions and strengthen community building has become a social transition period to resolve social conflicts, maintain social stability and promote economic development, to meet the needs of the masses, to strengthen socialist spiritual civilization, to expand grassroots democracy, self-realization of urban residents education, self-management, self-service, and to improve the management of urban 
modernization level of necessary requirement. Community sport is an important part of community services and community cultural construction. Services, community building communities of the mid-1980s have proposed, started late, development time is short, weak basic resources (physical basic resources are more weak), and all kinds of living needs of residents has grown rapidly, the obvious contradiction between supply and demand, only the implementation of "Article block combining resources integration "type, complementary, in order to ensure the achievement of community services functions.

\section{Conclusion}

Social transformation is a special form of social change and an important driving force behind the evolution of social formations. China's current social transformation mainly constituted by two profound changes: First, the transition from a planned economy to a market economy; the second is from agriculture, the countryside, closed traditional society to industrial, urban, open, modern society change. Social transformation is transitional, progressive, holistic, long-term, complexes and so on. Socio-economic transformation and social restructuring in the impact of market competition mechanism, the transformation of government functions and reform "unit system", and the establishment of "community system" for reform and development and the rise of community sports city has an important social sports impact. Promote social transformation of urban community sports management system by the unit system shift to community institutions.

\section{References}

[1] Wang Kaizhen. Status and Development Trend of Chinese Urban Community Sports. 1996 National Urban Community Sports Work Conference Proceedings, 1997.

[2] Xiao Guoliang. The 21st Century Early Development Trend of China Mass Sports and Countermeasures. Guangzhou Physical Education Institute .2001,03.

[3] Tian Pu. The 21st Century Development Trend of Social Sports Harbin Institute of Physical Education .2001,03.

[4] Shen Jianhua. Other Community Sports Development of New Models-School District Shanghai Sports Institute of Physical Education. 1994, 4.

[5] Ren Hai, Etc. Developing Models of Urban Community Sports. Sport Science .1998, 4. 